\title{
ERCC1 siRNA ameliorates drug resistance to cisplatin in gastric carcinoma cell lines
}

\author{
WEI LI ${ }^{*}$, ZHIGANG JIE ${ }^{2}$, ZHENGRONG LI ${ }^{2 *}$, YI LIU ${ }^{2}$, QUAN GAN ${ }^{1}$, YIQIU MAO ${ }^{1}$ and XUEMIN WANG ${ }^{1}$ \\ ${ }^{1}$ Department of General Surgery, Jiangxi Provincial Corps Hospital, Chinese People's Armed Police Force, Nanchang, \\ Jiangxi 330003; ${ }^{2}$ Department of General Surgery, The First Affiliated Hospital of Nanchang University, \\ Nanchang, Jiangxi 330006, P.R. China
}

Received July 7, 2013; Accepted February 24, 2014

DOI: $10.3892 / \mathrm{mmr} .2014 .2112$

\begin{abstract}
The present study examined the effects of cisplatin (DDP) on gastric carcinoma cells by inhibiting the expression of excision repair cross-complementing 1 (ERCC1) using RNA interference (RNAi). mRNA and protein expression of ERCC1 were measured in various gastric carcinoma cell lines using reverse transcription polymerase chain reaction (RT-PCR) and western blot analysis. Cells were treated with different concentrations of DDP and the cell viability was measured using an MTT assay. The correlation between the expression of the ERCC1 gene and the resistance to DDP in the cells was determined. The specific ERCC1 small interfering RNA (siRNA) was synthesized and then transfected into SGC-7901/DDP cells. Alterations in intracellular ERCC1 mRNA expression and protein levels were detected using RT-PCR and western blot analysis, the number of apoptotic cells were measured using flow-cytometry and the cell viability was measured using an MTT assay. The gene expression of ERCC1 correlated with the resistance to DDP of the cells. mRNA expression of ERCC1 was significantly reduced $24 \mathrm{~h}$ following transfection of ERCC1 siRNA compared with the mock control group. In addition, the number of apoptotic cells was increased and cell viability was significantly decreased in the ERCC1 siRNA-transfected group compared with the mock control group, suggesting that the sensitivity of SGC-7901/DDP cells to DDP had significantly increased. Cells transfected with siRNA1, siRNA2 and siRNA3 were significantly more sensitive to DPP (161, 381 and 249\%, respectively) compared with the mock controls $(\mathrm{P}<0.05)$. The results of the present study showed that drug resistance to DDP in gastric carcinoma is correlated with increased expression of
\end{abstract}

Correspondence to: Professor ZhiGang Jie, Department of General Surgery, The First Affiliated Hospital of Nanchang University, 17 Yongwaizheng Road, Nanchang, Jiangxi 330006, P.R. China E-mail: jiezg123@126.com

*Contributed equally

Key words: gastric carcinoma, cisplatin, drug resistance, ERCC1 gene, siRNA
ERCC1; therefore, inhibition of ERCC1 by siRNA may ameliorate resistance to DDP in gastric carcinoma.

\section{Introduction}

Gastric cancer is currently the third most common type of cancer and is predicted to remain a significant burden in China during the next decade (1). Surgery is the primary strategy used for managing early-stage and locally-advanced gastric cancer. However, most patients are diagnosed at the advanced stages of gastric cancer, when surgical eradication is not possible (2). Even following radical surgery, the majority of patients with advanced gastric cancer develop local or distant recurrences and metastases. Growing evidence appears to instead support the use of adjuvant chemotherapy, and surgery alone is no longer the standard treatment for patients with resectable gastric cancer (3-5).

Fluorouracil coupled with cisplatin (DPP) is a common combination regimen used in patients with advanced gastric cancer $(6,7)$. DDP is a widely used anticancer drug and exerts its activity by inducing the formation of several types of DNA adducts $(8,9)$, resulting in the inhibition of DNA synthesis, function and transcription. Resistance, however, has limited the efficacy of these drugs in the majority of patients with gastric cancer. Although DDP resistance is multifactorial, the most important resistance mechanism to platinum drugs has been attributed to enhanced tolerance and repair of DNA damage through the nucleotide-excision-repair (NER) pathway $(5,10)$. The NER pathway is highly conserved and is one of the major DNA repair pathways in mammalian cells that counteracts the formation of genetic damage (11). The NER pathway repairs bulky lesions, including pyrimidine dimers, other photo-products, large chemical adducts and cross-links (12). The NER pathway is the main mechanism for the removal of DPP adducts from genomic DNA. It involves at least four steps: i) Damage recognition by a complex of bound proteins, including xeroderma pigmentosum, complementation group $\mathrm{C}$ (XPC); ii) unwinding of the DNA by the transcription factor II human (TFIIH) complex that includes XPD; iii) removal of the damaged single-stranded fragments (usually 27-30 bp) by molecules including an excision repair cross-complementing 1 (ERCC1) and XPF complex; and iv) synthesis by DNA polymerases (13). 
The ERCC1 protein has a key role in NER (14) and accounts for the majority of platinum-DNA adduct repair. ERCC1 interacts with other genes, including XPA and XPF, in the NER pathway to guide 5'-incision activity in DNA repair (15). Increased levels of ERCC1 mRNA are associated with cellular and clinical resistance to platinum compounds and to platinum-based chemotherapy in non-small-cell lung carcinoma (NSCLC) and gastric cancer (16).

Small interfering RNA (siRNA) technology is a powerful method used to downregulate gene expression, and it has been widely used for target identification and to study gene function $(17,18)$. The technique takes advantage of the endogenous RNA-induced silencing complex (RISC), which is capable of separating the antisense strand of the siRNA and delivering it to its complementary mRNA sequence (19), leading to homology-dependent degradation of the mRNA strand. Using RNA interference (RNAi), gastric cancer cells resistant to DDP may become susceptible once more when ERCC1 mRNA expression is downregulated. Inhibition of ERCC1 expression may therefore present an interesting therapeutic strategy for the treatment of gastric cancer.

In the present study, the correlation between the expression of ERCC1 and the resistance to DDP in gastric carcinoma cells was investigated. ERCC1 gene expression was then downregulated by transfection of specific ERCC1 siRNA into SGC-7901/DDP gastric carcinoma cells, which are resistant to DDP. The number of apoptotic cells was measured using flow cytometry and cell viability was measured using an MTT assay in order to investigate whether downregulation of ERCC1 was able to overcome the resistance of gastric carcinoma cells to DDP.

\section{Materials and methods}

Cell culture. The human gastric cancer cell lines BGC-803, SGC-7901 and SGC-7901/DDP were obtained from Nanjing KeyGen Biotech Co.,Ltd. (Nanjing, China). The three cell lines were cultured in RPMI-1640 medium supplemented with 10\% fetal bovine serum (FBS; Gibco-BRL, Carlsbad, CA, USA) and incubated at $37^{\circ} \mathrm{C}$ in a $5 \% \mathrm{CO}_{2}$ atmosphere in a humidified incubator. A total of $1 \mathrm{mg} / \mathrm{l}$ DDP (Qilu Pharmaceutical Co., Ltd., Jinan, China) was added to the SGC-7901/DDP cells to maintain the resistance against DDP until three days prior to the start of the experiment.

Design, synthesis and transfection of ERCC1 siRNA. Three target sites within the ERCC1 gene were selected from the human ERCC1 mRNA sequence (GenBank Accession no. NM_0001983). The National Centre for Biotechnology Information (NCBI) Basic Local Alignment Search Tool (BLAST; http://blast.ncbi.nlm.nih.gov/Blast) was used to confirm the specificity of the target site to ERCC1. The siRNA-ERCC1 pairs were synthesized by Guangzhou RiboBio, Co., Ltd. (Guangzhou, China). The sequences were as follows: i) ERCC1 siRNA1 target sequence, 5'-GCCCTTATTCCGATCTACA-3', sense, 5'-GCCCUU AUUCCGAUCUACA dTdT-3' and antisense, 3'-dTdT CGGGAAUAAGGCUAGAUGU-5'; ii) ERCC1 siRNA2 target sequence, 5'-CGACGTAATTCCCGACTAT-3', sense, 5'-CGA CGUAAUUCCCGACUAU dTdT-3' and antisense, 3'-dTdT
GCUGCAUUAAGGGCUGAUA-5'; iii) ERCC1 siRNA3 target sequence, 5'-CCGTGAAGTCAGTCAACAA-3' sense, 5'-CCGUGAAGUCAGUCAACAA dTdT-3' and antisense, 3'-dTdT GGCACU UCAGUCAGUUGUU-5'. The cells were transfected with the siRNA duplexes using Lipofectamine 2000 (Invitrogen Life Technologies, Carlsbad, CA, USA) in accordance with the manufacturer's instructions. It was determined from the results of the preliminary experiments using cy3-labeled siRNA with the optimal transfection concentration and time being $50 \mathrm{~nm}$ and $24 \mathrm{~h}$, respectively.

Total RNA extraction and reverse transcription-polymerase chain reaction (RT-PCR) analysis. The total cellular RNA was extracted using a TRIzol kit (Invitrogen Life Technologies) in accordance with the manufacturer's instructions. RT-PCR was conducted using an RT-PCR kit (Invitrogen Life Technologies) with $\beta$-actin as a reference gene. The primer sequences used were as follows: ERCC1 (276 bp) forward, 5'-CCGCCAGCAAGGAAGAAA-3' and reverse, 5'-CTGCCGAGGGCTCACAAT-3'; $\beta$-actin (438 bp) forward, 5'-GTGGACATCCGCAAAGAC-3' and reverse, 5'-GCTGTCACCTTCACCGTTC-3'. RT-PCR was performed under the following conditions: $94^{\circ} \mathrm{C}$ for $5 \mathrm{~min}$, followed by 30 cycles of $94^{\circ} \mathrm{C}$ for $45 \mathrm{sec}, 51^{\circ} \mathrm{C}$ for $45 \mathrm{sec}$ and $72^{\circ} \mathrm{C}$ for $45 \mathrm{sec}$. The final extension was at $72^{\circ} \mathrm{C}$ for $5 \mathrm{~min}$. Results were normalized against the concentration of $\beta$-actin RNA, which also was determined using RT-PCR.

Western blot analysis. The cells were seeded on six-well plates at a concentration of $1 \times 10^{6} / \mathrm{ml}$ per well. The cells were then washed twice with ice-cold phosphate-buffered saline (PBS) and lysed with $1 \mathrm{X}$ SDS loading buffer. Total protein was extracted and quantified using an ultraviolet spectrophotometer (UV-2450; Shimadzu, Kyoto, Japan). A 15\% SDS-PAGE was performed, the products then transferred to a nitrocellulose (NC) membrane (Pierce Biotechnology, Inc., Rockford, IL, USA) and incubated for $2 \mathrm{~h}$. Membranes were blocked using PBS containing $0.1 \%$ Tween-20 and 5\% non-fat milk. Membranes were then probed with a primary antibody against ERCC1 (1:100 dilution; Santa Cruz Biotechnology, Inc., Santa Cruz, CA, USA) for $1 \mathrm{~h}$. Horseradish peroxidase conjugated to anti-mouse immunoglobulin $\mathrm{G}$ was used at 1:5,000 dilution as a secondary antibody. The blotted proteins were detected using an enhanced chemiluminescence detection system (Amersham Pharmacia Biotech, Amersham, UK). The grey scale calibration of images (western blot analysis and RT-PCR) were detected using ImageTool 3.0 (UTHSCSA, San Antonio, TX, USA).

MTT assay. Cells were plated onto 96-well plates at a cell concentration of $1 \times 10^{5} / \mathrm{ml}$ in a volume of $50 \mu \mathrm{l}$. Different concentrations of DDP were added to the wells and the cells were incubated at $37^{\circ} \mathrm{C}$ for $48 \mathrm{~h}$ in $5 \% \mathrm{CO}_{2}$. The MTT (Sigma, St. Louis, MO, USA) assay protocol was as follows: $15 \mu 1$ MTT solution was added to each well and the cells incubated at $37^{\circ} \mathrm{C}$ for $4 \mathrm{~h}$. The wells were then centrifuged at 2,000 $\mathrm{x}$ g for $10 \mathrm{~min}$ and the supernatant was discarded. Dimethyl sulfoxide $(100 \mu \mathrm{l})$ was added and the wells were then oscillated for $10 \mathrm{~min}$. The absorbance values of each well were subsequently measured at $570 \mathrm{~nm}$ using a microplate reader 
(Bio-Rad 3550; Bio-Rad, Hercules, CA, USA) and the optical density (OD) for each treatment was obtained. Each condition had three duplicate wells and each experiment was repeated three times. Cell viability was calculated using the ODs as follows: Tumor cell growth inhibition rate $(\%)=($ control group OD - treatment group OD)/(control group OD) x100. The half maximal inhibitory concentration $\left(\mathrm{IC}_{50}\right)$ was derived from the tumor cell growth inhibition dose-response curve and the drug resistance was calculated.

Apoptosis detection. SGC-7901/DDP cells were transfected with $50 \mathrm{~nm}$ siRNA1, siRNA2, siRNA3 and negative control (NC-control), respectively. The NC-control was transfected with a negative sequence and a Mock control was also set up without transfection. Twenty-four hours following transient transfection, cells were washed twice with PBS and then suspended in $1 \mathrm{X}$ binding buffer at a concentration of $1 \times 10^{6} / \mathrm{ml}$ ). The suspended cells $\left(100 \mu 1\right.$, density $\left.1 \times 10^{6} / \mathrm{ml}\right)$ were transferred to a 5-ml test tube, and $5 \mu \mathrm{l}$ Annexin V-fluorescein isothiocyanate (FITC) and propidium iodide (PI; BD Biosciences, Franklin Lakes, NJ, USA) were added The cells were gently agitated at room temperature in the dark for $15 \mathrm{~min}$. A total of $400 \mu 11 \mathrm{X}$ binding buffer was then added, flow cytometry was performed and apoptosis detected within $1 \mathrm{~h}$.

Statistical analysis. The data were analyzed by analysis of variance (ANOVA) using the SPSS 16.0 software (SPSS Inc., Chicago, IL, USA). All data are presented as the mean \pm standard error for three independent experiments. Student's t-test and two-way ANOVA were applied to evaluate statistical significance. $\mathrm{P}<0.05$ was considered to indicate a statistically significant difference between values.

\section{Results}

Expression of ERCC1 in human gastric carcinoma cell lines. BGC-803, SGC-7901 and SGC-7901/DDP cells in the logarithmic growth phase were harvested. mRNA and protein expression levels of ERCC1 in each group were detected using RT-PCR and western blot analysis, respectively (Fig. 1A and $\mathrm{B})$. ERCC1 gene expression was observed in all three gastric carcinoma cell lines; however, expression levels of ERCC1 in the cell line resistant to DDP (SGC-7901/DDP) were significantly higher compared with the other two cell lines. Using ImageTool analysis, it was demonstrated that the expression levels of ERCC1 mRNA in SGC-7901 and BGC-803 cells were significantly decreased compared with SGC-7901/DDP ( $\sim 32.5$ and $51.4 \%$ respectively; $\mathrm{P}<0.05)$. Expression levels of ERCC1 protein in SGC-7901 and BGC-803 cells were also significantly decreased compared with SGC-7901/DDP cells ( 33.1 and 57.7\%, respectively; $\mathrm{P}<0.05$ ) (Fig. 1C)

Sensitivity of different cells to DDP. The inhibition of cell viability following treatment with DDP at eight different concentrations was measured using the MTT assay and a dose-response curve was obtained (Fig. 2). The $\mathrm{IC}_{50}$ values of SGC-7901/DDP, SGC-7901 and BGC-803 cells were $15.70 \pm 0.37,5.53 \pm 0.13$ and $4.59 \pm 0.58 \mu \mathrm{g} / \mathrm{ml}$, respectively. SGC-7901/DDP cell resistance was 2.83-fold greater than that of SGC-7901 cells and 3.42-fold greater than that of
$\mathbf{A}$

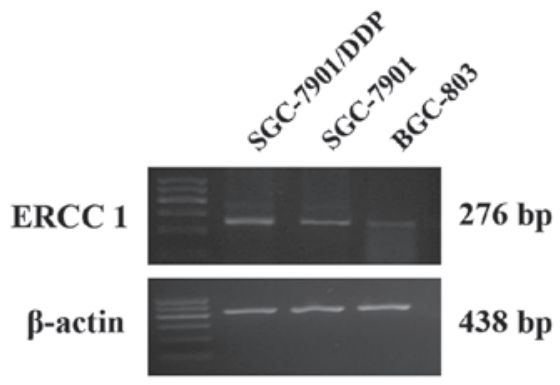

B

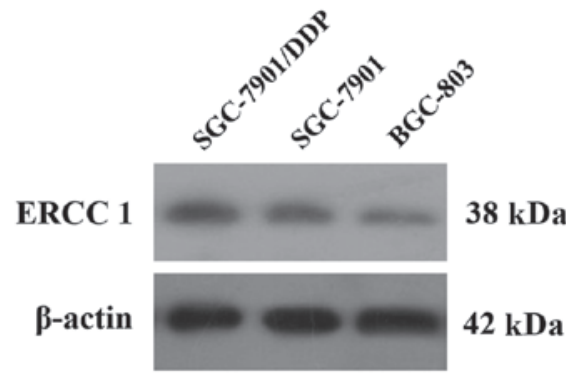

C

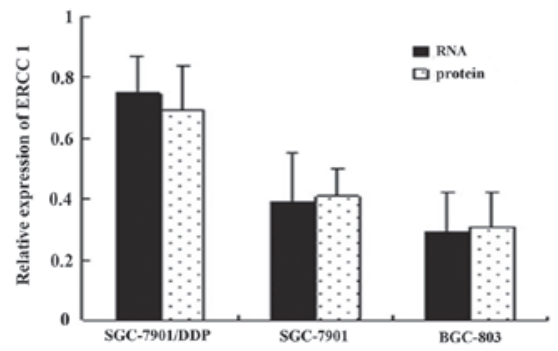

Figure 1. mRNA expression of ERCC1 in BGC-803, SGC-7901 and SGC-7901/DDP cell lines. (A) Semi-quantitative reverse transcription-polymerase chain reaction analysis of ERCC1 mRNA expression in the three gastric carcinoma cell lines. (B) ERCC1 protein expression levels in the three cell lines detected using western blot analysis. (C) Ratio of ERCC1 mRNA and protein expression levels compared with $\beta$-actin. Expression levels of the ERCC1 protein and the mRNA level in SGC-7901 and BGC-803 cells were significantly decreased compared with SGC-7901/DDP cells $(\mathrm{P}<0.05)$. Data are presented as the mean \pm standard error. Each experiment was repeated four times. ERCC1, excision repair cross-complementing 1.

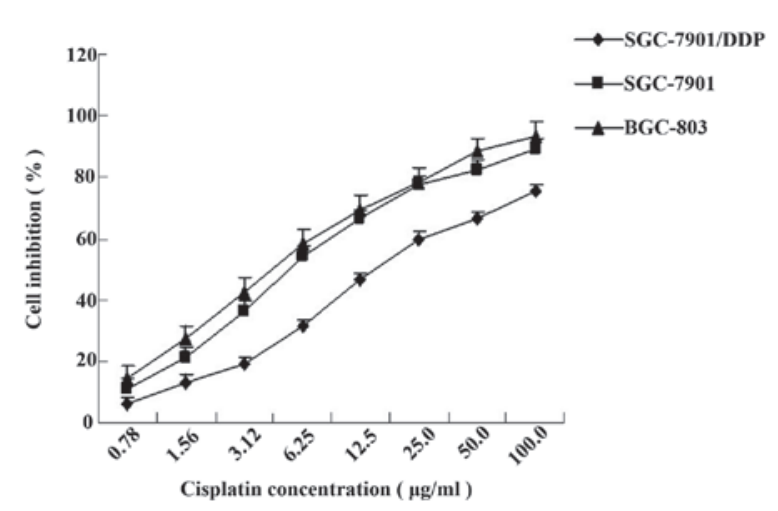

Figure 2. Dose-response curve for the three gastric carcinoma cell lines $48 \mathrm{~h}$ following treatment with cisplatin (DDP).

BGC-803 cells. Using correlation analysis, it was demonstrated that resistance to DDP in gastric carcinoma cells is associated with ERCC1 gene expression $(\mathrm{P}<0.05)$. 
siRNA-mediated downregulation of ERCC1 expression. The SGC-7901/DDP cells were transfected with $50 \mathrm{~nm}$ siRNA1, siRNA2, siRNA3 and NC-control. A control group without transfection (mock) was also set up. The most efficient transient transfection time was found to be $24 \mathrm{~h}$; therefore, at the this time-point, cells from each group were collected and ERCC1 mRNA and protein expression levels were detected using RT-PCR and western blot analysis, respectively (Fig. 3A and B). ImageTool software analysis results showed that ERCC1 mRNA and protein expression of SGC-7901/DDP cells following transfection with siRNA were significantly lower compared with non-transfected cells. The ERCC1 gene mRNA expression was reduced by $30.5,55.6$ and $23.7 \%$ compared with the control group $(\mathrm{P}<0.05)$ and protein expression was reduced by $28.9,64.7$ and $56.3 \%$ compared with the control group $(\mathrm{P}<0.05)$ for the siRNA1, siRNA2 and siRNA3 groups, respectively. However, the greatest inhibitory effect of siRNA on the ERCC1 gene expression was observed in the siRNA2 group. Gene expression of ERCC1 in the NC-control group was not significantly different from the expression in the non-transfected group ( $\mathrm{P}>0.05)$ (Fig. 3C).

Increased apoptosis in SGC-7901/DDP cells caused by downregulation of ERCC1. SGC-7901/DDP cell apoptosis was detected using Annexin V-FITC/PI double staining and cells were analyzed using flow cytometry $24 \mathrm{~h}$ following transfection. It was demonstrated that the percentage of apoptotic cells among the SGC-7901/DDP cells not transfected with siRNA (mock group) was $7.09 \pm 1.18 \%$, while the percentage of apoptotic cells in the siRNA1, siRNA2 and siRNA3 transfected groups was comparatively greater at $19.55 \pm 3.18,44.10 \pm 2.76$ and $33.28 \pm 2.19 \%$, respectively. The siRNA2-transfected cells showed the greatest number of apoptotic cells, significantly higher than the untransfected group $(\mathrm{P}<0.05$; Fig. $4 \mathrm{~A}$ and $\mathrm{B})$. The percentage of apoptotic cells in the NC-control group was similar to that in the untransfected (mock) group.

Increased DDP sensitivity in SGC-7901/DDP cells transfected with ERCC1 siRNA. Cell viability was measured in each group using the MTT assay $24 \mathrm{~h}$ following transient transfection and treatment with different concentrations of DDP. It was shown that the sensitivity to DDP in SGC-7901/DDP cells was significantly increased following ERCC1 siRNA transfection. The $\mathrm{IC}_{50}$ values of mock and $\mathrm{NC}$-control groups were $15.70 \pm 0.37$ and $16.12 \pm 0.49 \mu \mathrm{g} / \mathrm{ml}$, respectively. The $\mathrm{IC}_{50}$ values of the siRNA1-, siRNA2- and siRNA3-transfected groups $(9.74 \pm 0.22,4.12 \pm 0.47$ and $6.30 \pm 0.71 \mu \mathrm{g} / \mathrm{ml}$, respectively) were 1.61-, 3.81- and 2.49-fold greater than that of the mock group, respectively ( $\mathrm{P}<0.05 ;$ Fig. 5$)$. The results of the MTT assay suggest that the attenuation of the resistance of SGC-7901/DDP cells to DDP is positively correlated with the reduction in expression of ERCC1.

\section{Discussion}

Platinum-based chemotherapy has been shown to increase survival rates and improve the quality of life for patients with advanced gastric cancer. Therapies based on DDP and its third generation analogue, oxaliplatin, have significant
$\mathbf{A}$

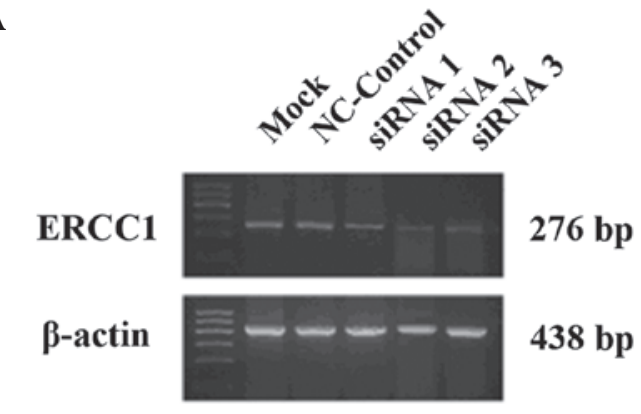

B

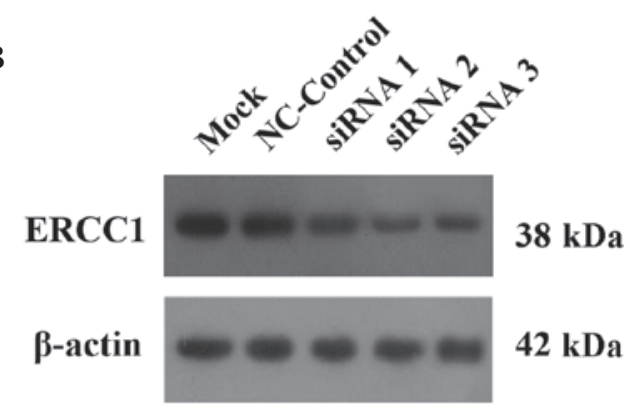

C

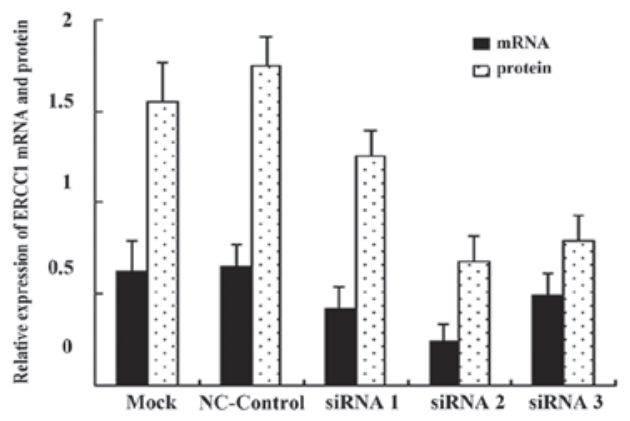

Figure 3. mRNA and protein expression levels of ERCC1 $24 \mathrm{~h}$ following siRNA transfection in SGC-7901/DDP cells. (A) Reverse transcription-polymerase chain reaction showing the expression of ERCC1 mRNA in each group following transfection. (B) Western blot analysis showing ERCC1 protein expression levels $24 \mathrm{~h}$ following siRNA transfection in SGC-7901/DDP cells. (C) Ratio of ERCC1 mRNA and protein expression levels compared with $\beta$-actin. Data are presented as the mean \pm standard error. The mRNA and protein expression of ERCC1 was decreased compared with the control group $(\mathrm{P}<0.05)$. Each experiment was repeated four times. ERCC1, excision repair cross-complementing 1; siRNA, small interfering RNA; NC-control, negative control group.

clinical benefits $(20,21)$. Drug resistance, however, is a major obstacle in chemotherapy, often leading to treatment failure in patients with cancer (22). Several resistance mechanisms to platinum compounds have been identified. These include reduced intracellular drug accumulation by changing the profile of drug influx or efflux molecules, inactivation of the drug by glutathione as a result of alterations in cellular transport, enhanced DNA damage repair or increased tolerance of DNA damage (23-25). NER is the only known mechanism in mammalian cells for the removal of bulky, helix-distorting DNA adducts produced by platinum agents and appears to be a key pathway involved in mediating resistance or sensitivity to platinum chemotherapeutic agents $(26,27)$. NER comprises $\geq 11$ factors composed of $>30$ proteins, whose combined activities find and excise DNA damage in the genome. The 
A
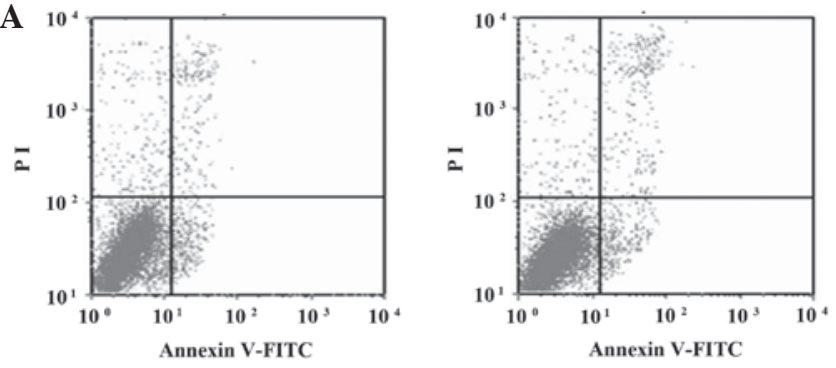

Mock

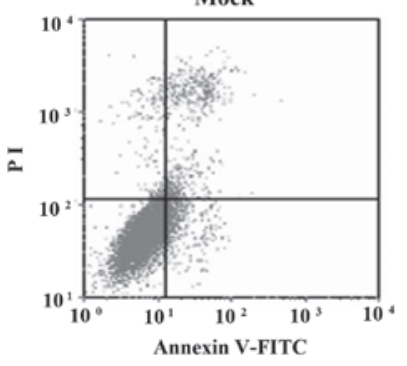

SIRNA 1
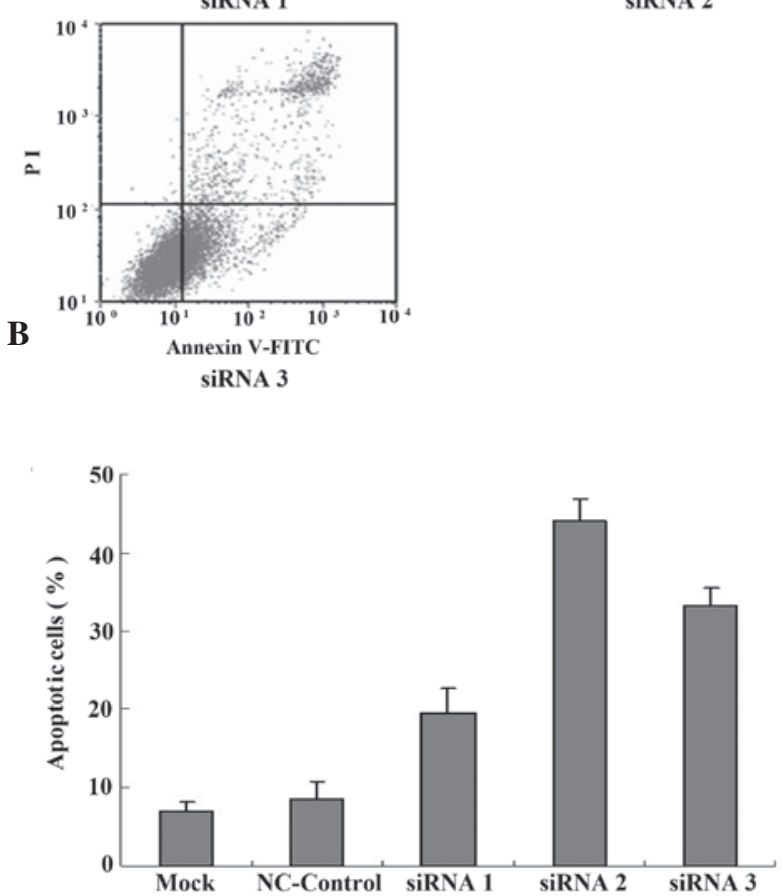

Figure 4. (A) Effect of ERCC1 siRNA on the percentage of apoptotic cells in each group in the SGC-7901/DDP cell line measured using flow cytometry with Annexin V-FITC/PI double staining. (B) Percentage of apoptotic cells in each group. NC-control, negative control group. FITC, fluorescein isothiocyanate; ERCC1, excision repair cross-complementing 1; siRNA, smal interfering RNA; PI, propidium iodide; NC-control, negative control group.

ERCC1 protein is an important part of NER. It forms a heterodimer with XPF and is involved in the cleavage of the damaged DNA strand 5 ' to the DNA lesion.

The ERCC1 gene is located on the human 19q13.2-q13.3 chromosome. It is $15 \mathrm{~kb}$ in length; however, only $1.1 \mathrm{~kb}$ of the mRNA encodes the protein, which is 297 amino acids long and has a molecular weight of $32.5 \mathrm{kDa}$. The ERCC1 protein is involved in DNA chain removal and damage recognition; therefore, it is involved in the resistance to chemotherapy (28). A previous study found that, in patients with advanced gastric cancer treated with 5-fluorouracil (FU) and DDP, expression levels of ERCC1 were correlated with response and overall

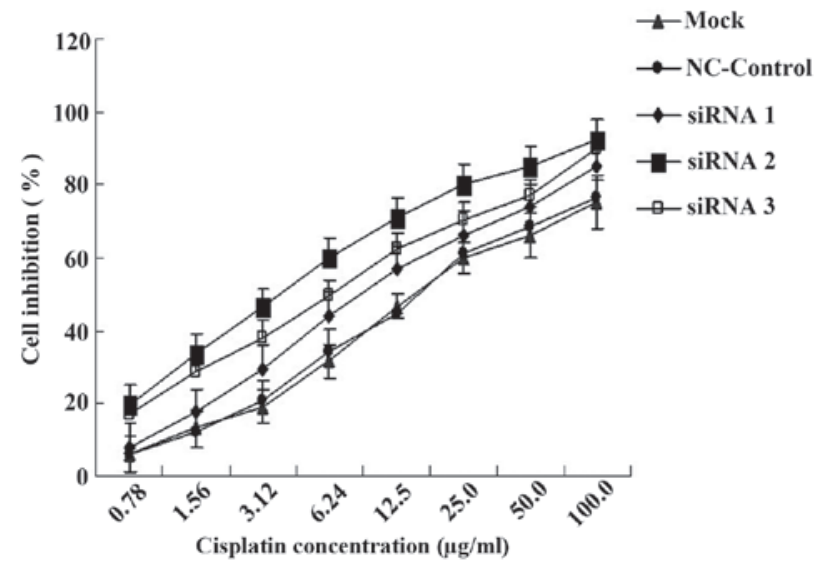

Figure 5. Dose-response curve for each group in the SGC-7901/DDP cell line $48 \mathrm{~h}$ following treatment with cisplatin (DDP). The $\mathrm{IC}_{50}$ values of the siRNA-tansfected groups were greater than the mock group and the NC-control group $(\mathrm{P}<0.05)$. NC-control, negative control group; siRNA, small interfering RNA.

survival (29). In the present study, ERCC1 gene expression was measured in three different gastric carcinoma cell lines, BGC-803, SGC-7901 and SGC-7901/DDP. The data demonstrated that the expression levels of ERCC1 in SGC-7901/DDP cells were significantly higher compared with those in the other two cell lines $(\mathrm{P}<0.05)$. The results of the MTT assay showed that the resistance of SGC-7901/DDP cells was $283 \%$ that of the SGC-7901 cells and $342 \%$ that of the BGC-803 cells. It was also shown that the expression of ERCC1 is correlated with the resistance to DPP in gastric carcinoma. Therefore, the present study provides evidence in vitro that the expression of the ERCC1 gene is correlated with the resistance to DDP.

It has been demonstrated that RNAi technology is more feasible and exerts enhanced inhibitory effects on gene expression compared with antisense RNA technology (30). RNAi is a small piece of RNA produced by host cells during the cleavage of foreign double-stranded RNA (dsRNA). These small interfering RNAs bind to the target DNA and induce the degradation of the specific RNA, downregulating gene expression. This process is called RNAi (31-34). In the present study, ERCC1 siRNA was synthesized and transfected into SGC-7901/DDP cells to determine whether it was capable of reversing the resistance to DPP in SGC-7901/DDP cells. The results from a preliminary study using a Cy3-labeled negative control revealed that the optimum conditions for transfection were $50 \mathrm{~nm}$ siRNA for $24 \mathrm{~h}$. Another preliminary study using GAPDH as a target gene was performed to ensure that the siRNA was specifically inhibiting target gene expression. Positive control GAPDH siRNA was synthesized and the results confirmed that the chemically synthesized siRNA produced a specific and effective inhibitory effect on the target gene. In the main experiment, it was found that the three pairs of siRNA significantly decreased the expression of ERCC1 compared with the NC-control and mock groups $(\mathrm{P}<0.05)$. The results of the MTT assay showed that following transfection with siRNA1, siRNA2 and siRNA3, the sensitivity to DDP of the three groups significantly increased by 1.61 -, 3.81- and 2.49-fold, respectively. The results also suggested that the reversal of DDP resistance of SGC-7901/DDP cells 
was correlated with the reduction in the expression of ERCC1. The data from the flow cytometry assay demonstrated that the rate of apoptosis increased following transfection with ERCC1 siRNA. This suggests that ERCC1 siRNA promotes apoptosis and the reversal of DPP resistance may be associated with the regulation of the induction of tumor cell apoptosis.

The present study demonstrated that ERCC1 gene expression levels in gastric cancer are associated with the resistance to DDP. RNAi reduces ERCC1 gene expression and is capable of regulating the gastric cancer cell cycle, inducing cell apoptosis and reversing drug resistance to chemotherapy. This study provides experimental evidence for clinical personalized chemotherapy and a novel strategy using gene therapy to reverse chemotherapy resistance in patients with gastric cancer.

\section{Acknowledgements}

The authors would like to thank Dr He-Ping Chen (Department of Pharmacology of Medical College of Nanchang University) for his excellent technical assistance. This study was supported by Jiangxi Science and Technology Department.

\section{References}

1. Wei J, Zou Z, Qian X, et al: ERCC1 mRNA levels and survival of advanced gastric cancer patients treated with a modified FOLFOX regimen. Br J Cancer 98: 1398-1402, 2008.

2. Wang TS, Ding QQ, Guo RH, Shen H, Sun J, Lu KH, You SH, Ge HM, Shu YQ and Liu P: Expression of livin in gastric cancer and induction of apoptosis in SGC-7901 cells by shRNA-mediated silencing of livin gene. Biomed Pharmacother 64: 333-338, 2010.

3. Hejna M, Wöhrer S, Schmidinger $M$ and Raderer $M$ : Postoperative chemotherapy for gastric cancer. Oncologist 11: 136-145, 2006

4. Sakuramoto S, Sasako M, Yamaguchi T, et al: Adjuvant chemotherapy for gastric cancer with S-1, an oral fluoropyrimidine. N Engl J Med 357: 1810-1820, 2007.

5. Huang ZH, Hua D and Du X: Polymorphisms in p53, GSTP1 and XRCC1 predict relapse and survival of gastric cancer patients treated with oxaliplatin-based adjuvant chemotherapy. Cancer Chemother Pharmacol 64: 1001-1007, 2009.

6. Ruzzo A, Graziano F, Kawakami K, et al: Pharmacogenetic profiling and clinical outcome of patients with advanced gastric cancer treated with palliative chemotherapy. J Clin Oncol 24 1883-1891, 2006.

7. Wöhrer SS, Raderer M and Hejna M: Palliative chemotherapy for advanced gastric cancer. Ann Oncol 15: 1585-1595, 2004.

8. Chijiwa S, Masutani C, Hanaoka F, Iwai S and Kuraoka I: Polymerization by DNA polymerase eta is blocked by cisdiamminedichloroplatinum(II) 1,3-d(GpTpG) cross-link: implications for cytotoxic effects in nucleotide excision repair-negative tumor cells. Carcinogenesis 31: 388-393, 2010.

9. Helleday T, Petermann E, Lundin C, Hodgson B and Sharma RA: DNA repair pathways as targets for cancer therapy. Nat Rev Cancer 8: 193-204, 2008.

10. Kweekel DM, Gelderblom H and Guchelaar HJ: Pharmacology of oxaliplatin and the use of pharmacogenomics to individualize therapy. Cancer Treat Rev 31: 90-105, 2005.

11. Rechkunova NI and Lavrik OI: Nucleotide excision repair in higher eukaryotes: mechanism of primary damage recognition in global genome repair. Subcell Biochem 50: 251-277, 2010.

12. Goode EL, Ulrich CM and Potter JD: Polymorphisms in DNA repair genes and associations with cancer risk. Cancer Epidemiol Biomarkers Prev 11: 1513-1530, 2002.

13. Friedberg EC: How nucleotide excision repair protects against cancer. Nat. Rev. Cancer 1: 22-33, 2001.
14. Martin LP, Hamilton TC and Schilder RJ: Platinum resistance: the role of DNA repair pathways. Clin Cancer Res 14: 1291-1295, 2008.

15. Zhao H, Wang LE, Li D, Chamberlain RM, Sturgis EM and Wei Q: Genotypes and haplotypes of ERCC1 and ERCC2/XPD genes predict levels of benzo[a]pyrene diol epoxide-induced DNA adducts in cultured primary lymphocytes from healthy individuals: a genotype-phenotype correlation analysis. Carcinogenesis 29: 1560-1566, 2008.

16. Wang L, Wei J, Qian X, Yin H, Zhao Y, Yu L, Wang T and Liu B: ERCC1 and BRCA1 mRNA expression levels in metastatic malignant effusions is associated with chemosensitivity to cisplatin and/or docetaxel. BMC Cancer 8: 97, 2008.

17. Halder J, Kamat AA, Landen CN Jr, et al: Focal adhesion kinase targeting using in vivo short interfering RNA delivery in neutral liposomes for ovarian carcinoma therapy. Clin Cancer Res 12: 4916-4924, 2006.

18. Hannon GJ and Rossi JJ: Unlocking the potential of the human genome with RNA interference. Nature 431: 371-378, 2004.

19. Snygg AS and Elmroth SK: Expanding the chemical nature of siRNAs: oxaliplatin as metalation reagent. Biochem Biophys Res Commun 379: 186-190, 2009.

20. Ajani JA: Evolving chemotherapy for advanced gastric cancer. Oncologist 10 (Suppl 3): 49-58, 2005.

21. Park DJ and Lenz HJ: Determinants of chemosensitivity in gastric cancer. Curr Opin Pharmacol 6: 337-344, 2006.

22. Kang HC, Kim IJ, Park HW, Jang SG, Ahn SA, Yoon SN, Chang HJ, Yoo BC and Park JG: Regulation of MDK expression in human cancer cells modulates sensitivities to various anticancer drugs: MDK overexpression confers to a multi-drug resistance. Cancer Lett 247: 40-47, 2007.

23. Miyashita H, Nitta Y, Mori S, et al: Expression of copper-transporting P-type adenosine triphosphatase (ATP7B) as a chemoresistance marker in human oral squamous cell carcinoma treated with cisplatin. Oral Oncol 39: 157-162, 2003.

24. Nakayama K, Kanzaki A, Ogawa K, Miyazaki K, Neamati N and Takebayashi Y: Copper-transporting P-type adenosine triphosphatase (ATP7B) as a cisplatin based chemoresistance marker in ovarian carcinoma: comparative analysis with expression of MDR1, MRP1, MRP2, LRP and BCRP. Int J Cancer 101: 488-495, 2002.

25. Johnson NP, Hoeschele JD and Rahn RO: Kinetic analysis of the in vitro binding of radioactive cis- and trans-dichlorodiammineplatinum(II) to DNA. Chem Biol Interact 30: 151-169, 1980.

26. Marcuello E, Altés A, del Rio E, César A, Menoyo A and Baiget M: Single nucleotide polymorphism in the 5 ' tandem repeat sequences of thymidylate synthase gene predicts for response to fluorouracil-based chemotherapy in advanced colorectal cancer patients. Int J Cancer 112: 733-737, 2004.

27. Rabik CA and Dolan ME: Molecular mechanisms of resistance and toxicity associated with platinating agents. Cancer Treat Rev 33: 9-23, 2007.

28. Park CH, Bessho T, Matsunaga T and Sancar A: Purification and characterization of the XPF-ERCC1 complex of human DNA repair excision nuclease. J Biol Chem 270: 22657-22660, 1995.

29. Huang ZH, Hua D, Du X, Li LH, Mao Y, Liu ZH, Song MX and Zhou XK: ERCC1 polymorphism, expression and clinical outcome of oxaliplatin-based adjuvant chemotherapy in gastric cancer. World J Gastroenterol 14: 6401-6407, 2008.

30. Tavernarakis N, Wang SL, Dorovkov M, Ryazanov A and Driscoll M: Heritable and inducible genetic interference by double-stranded RNA encoded by transgenes. Nat Genet 24: 180-183, 2000.

31. Hannon GJ: RNA interference. Nature 418: 244-251, 2002.

32. Chang H: RNAi-mediated knockdown of target genes: a promising strategy for pancreatic cancer research. Cancer Gene Ther 14: 677-685, 2007.

33. Shao Y, Chan CY, Maliyekkel A, Lawrence CE, Roninson IB and Ding Y: Effect of target secondary structure on RNAi efficiency. RNA 13: 1631-1640, 2007.

34. Liu G, Wong-Staal F and Li QX: Development of new RNAi therapeutics. Histol Histopathol 22: 211-217, 2007. 